\title{
Compacted states and physical properties of soil controlled by the degree of saturation during compaction
}

\author{
Fumio Tatsuoka ${ }^{1, *}$ and Toru Miura $^{2}$ \\ ${ }^{1}$ Tokyo University of Science, Civil Engineering Department, Chiba, Japan \\ ${ }^{2}$ NTC Consultants Co., Ltd., Japan
}

\begin{abstract}
For satisfactory performance of soil structures, it is necessary to properly control soil compaction ensuring the physical properties of compacted soil required in design. Usually the dry density $\rho_{\mathrm{d}}$ and the water content $w$ are controlled in relation to the maximum dry density $\left(\rho_{\mathrm{d}}\right)_{\max }$ and the optimum water content $w_{\text {opt }}$ determined by laboratory compaction tests on a chosen representative sample at a certain compaction energy level CEL. Although CEL and soil type affect significantly $\left(\rho_{\mathrm{d}}\right)_{\max }, w_{\mathrm{opt}}$ and physical properties, they change inevitably, sometimes largely, in a given project while field CEL may not match the value used in the laboratory compaction tests. In comparison, the optimum degree of saturation $\left(S_{\mathrm{r}}\right)_{\text {opt }}$ (i.e., $S_{\mathrm{r}}$ when $\left(\rho_{\mathrm{d}}\right)_{\max }$ is obtained) and the normalized compaction curve (i.e., $\rho_{\mathrm{d}} /\left(\rho_{\mathrm{d}}\right)_{\max }$ vs. $S_{\mathrm{r}}-\left(S_{\mathrm{r}}\right)_{\text {opt }}$ relation) for given CEL and soil type are insensitive to variations in CEL and soil type and they are essentially fixed in a given project. Besides, the stress-strain and hydraulic properties of compacted soil are controlled by $\rho_{\mathrm{d}}$ and " $S_{\mathrm{r}}$ at the end of compaction relative to $\left(S_{\mathrm{r}}\right)_{\text {opt". It }}$ is proposed to control $w$ and CEL so that $S_{\mathrm{r}}=\left(S_{\mathrm{r}}\right)_{\mathrm{opt}}$ while $\rho_{\mathrm{d}}$ becomes large enough to ensure the physical properties required in design fully taking advantage of available field CEL on site. A case history of earth-fill dam construction in Japan following this soil compaction control method is reported.
\end{abstract}

\section{Introduction}

The stress-strain and hydraulic properties of compacted soil are controlled by not only soil type and dry density $\rho_{\mathrm{d}}$ (or the degree of compaction $D_{\mathrm{c}}=\rho_{\mathrm{d}}$ /" maximum dry density $\left(\rho_{d}\right)_{\max }$ for certain compaction energy level CEL"), but also the degree of saturation $S_{\mathrm{r}}$ during compaction [1, 2]. This is because the physical properties of compacted soil are controlled by the effective stress state and the micro-structure and both are controlled by the matric suction during compaction, which is a function of $S_{\mathrm{r}}$ during compaction. For a fixed $\rho_{\mathrm{d}}$, the strength/stiffness indexes (e.g., $G_{0}, \mathrm{CBR} \& k_{\mathrm{v}}$ ) become larger significantly as $S_{\mathrm{r}}$ decreases from the optimum degree of saturation $\left(S_{\mathrm{r}}\right)_{\text {opt }}$ (i.e., $S_{\mathrm{r}}$ when $\left(\rho_{\mathrm{d}}\right)_{\max }$ is obtained for given soil type and CEL). This fact implies that the physical properties of compacted soil cannot be estimated only from soil type and $\rho_{\mathrm{d}}\left(\right.$ or $D_{\mathrm{c}}$ ), but also $S_{\mathrm{r}}$ at the end of compaction $\left(S_{\mathrm{r}}\right)_{\text {EOC }}$ is necessary to know. To evaluate the design physical properties of compacted soil, the $S_{\mathrm{r}}$ value under considered design conditions (e.g., wet or saturated) is also necessary. The design physical properties under considered design conditions should be evaluated as a function of the values of $\left[D_{\mathrm{c}}\right]_{1 \mathrm{Ec}}$ and $\left(S_{\mathrm{r}}\right)_{\mathrm{EOC}}$ relative to $\left(S_{\mathrm{r}}\right)_{\mathrm{opt}}$ determined by relevant laboratory and/or field tests.

In usual practice, the values of $\rho_{\mathrm{d}}$ and water content $w$ of compacted soil are controlled related to their reference values, $\left(\rho_{\mathrm{d}}\right)_{\max }$ and the optimum water content $w_{\text {opt }}$, determined by standard laboratory compaction tests at a certain CEL (typically Standard Proctor, 1Ec) using a chosen representative sample. Although soil type and CEL affect significantly $\left(\rho_{\mathrm{d}}\right)_{\max }$ and $w_{\text {opt }}$, they change inevitably, sometimes largely, in a given project while field CEL may not match the value used in the laboratory. On the other hand, the major features of compaction characteristics can be represented by the following three empirical rules $\left.[1,2]: 1)\left(S_{\mathrm{r}}\right)_{\mathrm{opt}} ; 2\right)$ the normalized relationship between "the true degree of compaction $\left(D_{\mathrm{c}}\right)_{\mathrm{t}}=\rho_{\mathrm{d}} /\left(\rho_{\mathrm{d}}\right)_{\max }$ " and " $S_{\mathrm{r}}-\left(S_{\mathrm{r}}\right)_{\text {opt }}$ " for given soil type and CEL; and 3 ) the compaction coefficient $C$ in Eq. 1 expressing the effect of CEL on $\left(\rho_{\mathrm{d}}\right)_{\max }$ :

$$
R=\left(\rho_{\mathrm{d}}\right)_{\max } /\left[\left(\rho_{\mathrm{d}}\right)_{\max }\right]_{1 \mathrm{Ec}}=1+C \cdot \log (C E L / \mathrm{Ec})
$$

where, for a given soil type, $\left(\rho_{d}\right)_{\max }$ is the value for a certain CEL; and $\left[\left(\rho_{d}\right)_{\max }\right]_{1 E c}$ is the value when $\mathrm{CEL}=$ 1Ec. As shown later, unlike compaction curves on the $\rho_{\mathrm{d}}$ $-w$ plane, these three rules can be assumed to be fixed in a given project where the variations of soil type and CEL are limited by their control.

In this paper, it is shown that, by controlling $\left(S_{\mathrm{r}}\right)_{\mathrm{EOC}}$ and CEL based on these three empirical rules, soil compaction becomes much more efficient and objective properly controlling the soil properties than when not controlling them. As a case history showing the above, the restoration of Fujinuma dam that collapsed by the 2011 Off the Pacific Coast of Tohoku Earthquake (Fig. 1) is reported. The stress-strain properties of the fill materials, the numerical simulation of the collapse of the

\footnotetext{
* Corresponding author: tatsuoka@rs.noda.tus.ac.jp
} 
old dam and the predicted seismic behaviour of the new dam are reported elsewhere [3-5].

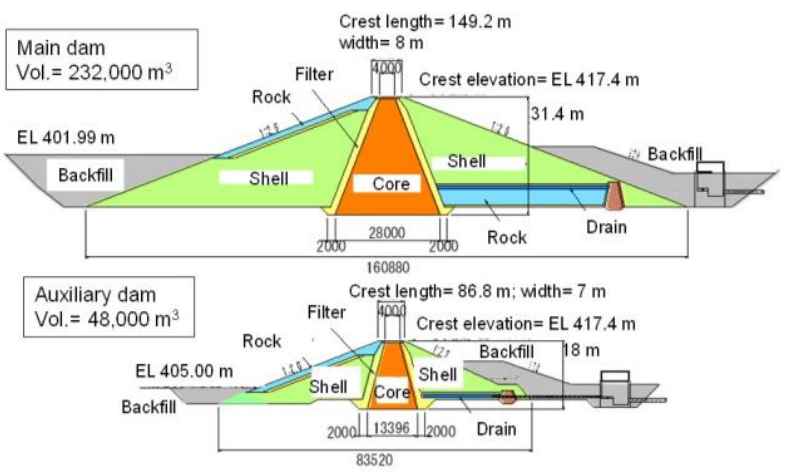

Fig. 1. Restored Fujinuma earth-fill dams [3].

\section{Physical properties}

\subsection{CBR (unsoaked and soaked)}

Tatsuoka [1] analyzed a large amount of unsoaked CBR data from full-scale compaction tests on sandy loam (Fig. 2a) using many actual compaction rollers. Figs. 2c $\& \mathrm{~d}$ show the unsoaked CBRs when $\left(S_{\mathrm{r}}\right)_{\mathrm{EOC}}=30-40 \%$ and $70-80 \%$ plotted against $\rho_{\mathrm{d}}$. Similar results were obtained for other $S_{\mathrm{r}}$ values. As the relation for each $S_{\mathrm{r}}$ value is unique for different compaction roller types and different numbers of pass $N$, they were fitted by Eq. 2 comprising uncoupled functions of $S_{\mathrm{r}}$ and $\rho_{\mathrm{d}}$ not including the water content $w$ and CEL as variables:

$$
C B R=f_{C B R}\left(S_{r}\right) \cdot\left(\rho_{d} / \rho_{w}-b\right)^{c}
$$

where $b=0.4$ and $c=0.95$ in this case; and $f_{\mathrm{CBR}}$ is a function of $\left(S_{\mathrm{r}}\right)_{\mathrm{EOC}}$ (Fig. 3a). Unsoaked CBR for given values of $\rho_{\mathrm{d}}$ and $S_{\mathrm{r}}$ can be obtained by Eq. 2 without referring to CEL in the field, which is usually unknown.

In Fig. 2b, the contours of unsoaked CBR by Eq. 2 and those of soaked CBR [1] are depicted. Soaked CBR is relevant to the design of soil structure after wetting/saturation. Compaction curve A is for $N=16$ in a typical full-scale compaction test series, while compaction curve $\mathrm{B}$ is by laboratory compaction tests (1Ec). Fig. $3 \mathrm{~b}$ shows the unsoaked and soaked CBR vs. $w$ relations along compaction curves $\mathrm{A}$ and $\mathrm{B}$. Commonly with them, when $S_{\mathrm{r}}<\left(S_{\mathrm{r}}\right)_{\mathrm{opt}}$, CBR is very large when unsoaked but drops largely upon soaking. When $S_{\mathrm{r}}=\left(S_{\mathrm{r}}\right)_{\text {opt }}$, CBR drops only slightly upon soaking, while soaked CBR is close to its maximum attained at a slightly lower $w$ along each relation. When $S_{\mathrm{r}}>\left(S_{\mathrm{r}}\right)_{\text {opt }}$, the drop of CBR upon soaking is negligible, whereas CBR is small and decreases largely with $w$ along each relation. Besides, CBR decreases with an increase in CEL at a fixed $w$, indicating the phenomenon of overcompaction. These trends imply that, to obtain sufficiently large strength/stiffness after wetting or saturation, the $S_{\mathrm{r}}=\left(S_{\mathrm{r}}\right)_{\text {opt }}$ state is the relevant compaction target irrespective of soil type and CEL and their variations. Importantly, other strength/stiffness indexes (e.g., the elastic shear modulus $G_{0}$, undrained shear strength and $E_{50}$ of soils by triaxial compression tests, cyclic undrained strength of saturated sandy soils, collapse upon wetting etc.) are also controlled by $\rho_{\mathrm{d}}$ and $\left(S_{\mathrm{r}}\right)_{\text {EOC }}(\operatorname{not} w)[1,2]$.

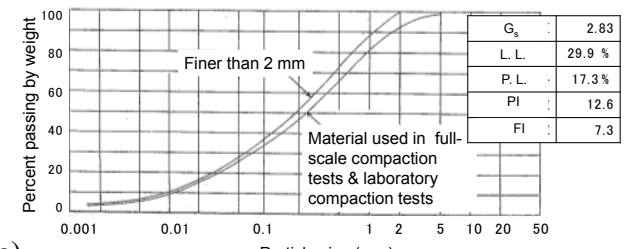

a)

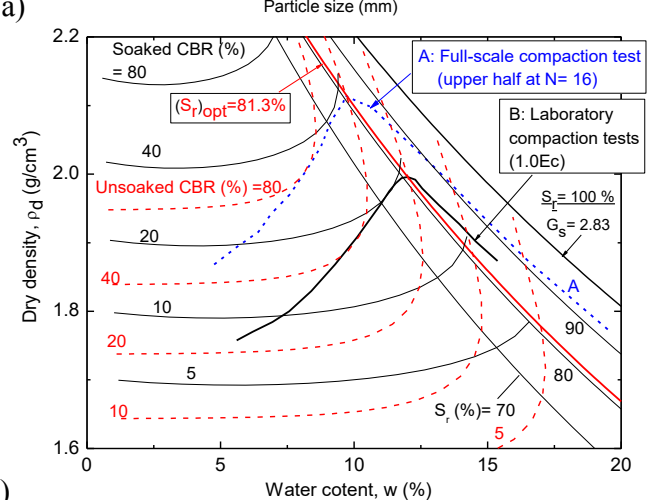

b)

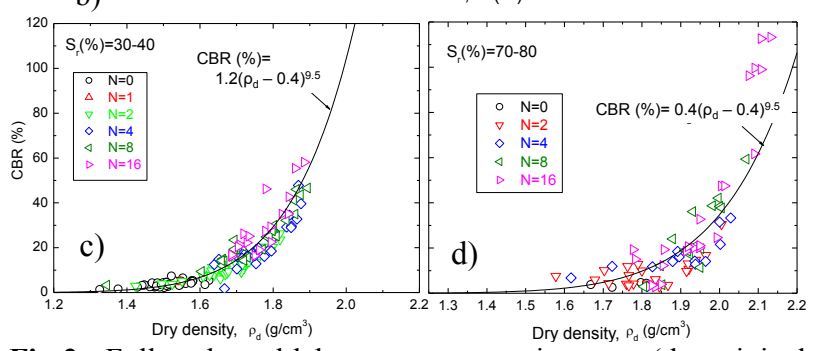

Fig 2. Full-scale and laboratory compaction tests (the original data reported in [6] and analyzed in [1]): a) test material; b) compaction curves and contours of unsoaked and unsoaked CBR; and c \& d) summarized unsoaked CBR vs. $\rho_{\mathrm{d}}$ relations for $S_{\mathrm{r}}=30-40 \%$ and $70-80 \%$.
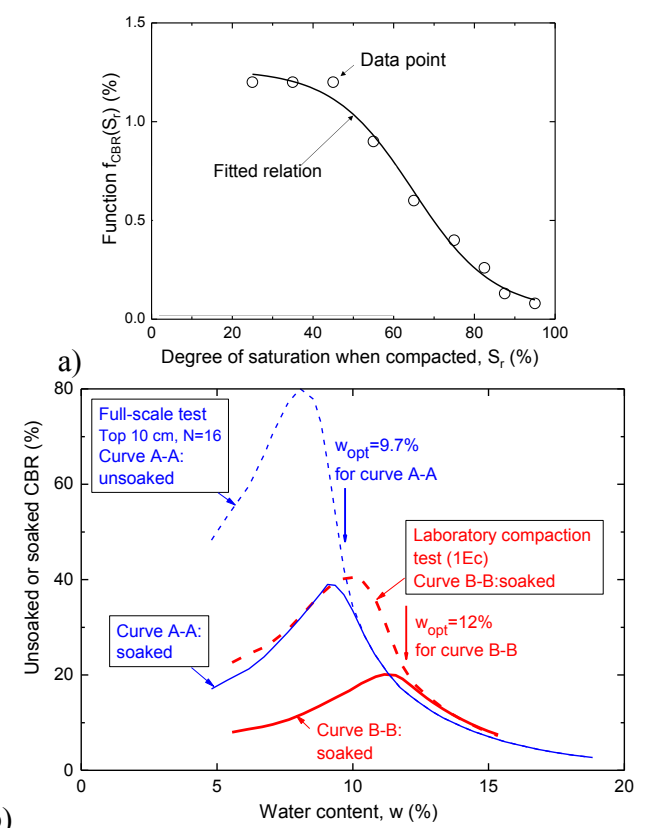

Fig. 3. a) Function expressing the effect of $S_{\mathrm{r}}$ on unsoaked CBR; and b) unsoaked \& soaked CBR vs. $w$ relations along compaction curves A \& B shown in Fig. $2 b[1,2]$. 


\subsection{Coefficient of hydraulic conductivity}

Fig. $4 \mathrm{~b}$ shows compaction curves by $1 \mathrm{Ec}$ and $4 \mathrm{Ec}$ of the sieved core material for Miboro dam (Fig. 4a) [6]. Fig. $4 \mathrm{c}$ shows the relationship between log. of the coefficient of saturated hydraulic conductivity $k$ and $w$ measured along compaction curves by five different CELs. When $\mathrm{CEL}=1 \mathrm{Ec}, k$ becomes the minimum at $w$ slightly higher than $\left(w_{\text {opt }}\right)_{1 \mathrm{Ec} .}$ " Compaction wetter than the optimum" is usually recommended for the design of fills impeding the hydraulic flow (e.g., earth fill dams, river dykes \& clay liners) $[7,8]$. However, $w_{\text {opt }}$ decreases with CEL. When $\mathrm{CEL}=4 \mathrm{Ec}$, a lower $k$ and a higher $\rho_{\mathrm{d}}$ are obtained at $w \approx$ $12 \%$, which is noticeably lower than $\left(w_{\mathrm{opt}}\right)_{1 \mathrm{Ec}} \approx 13.5 \%$.

b)
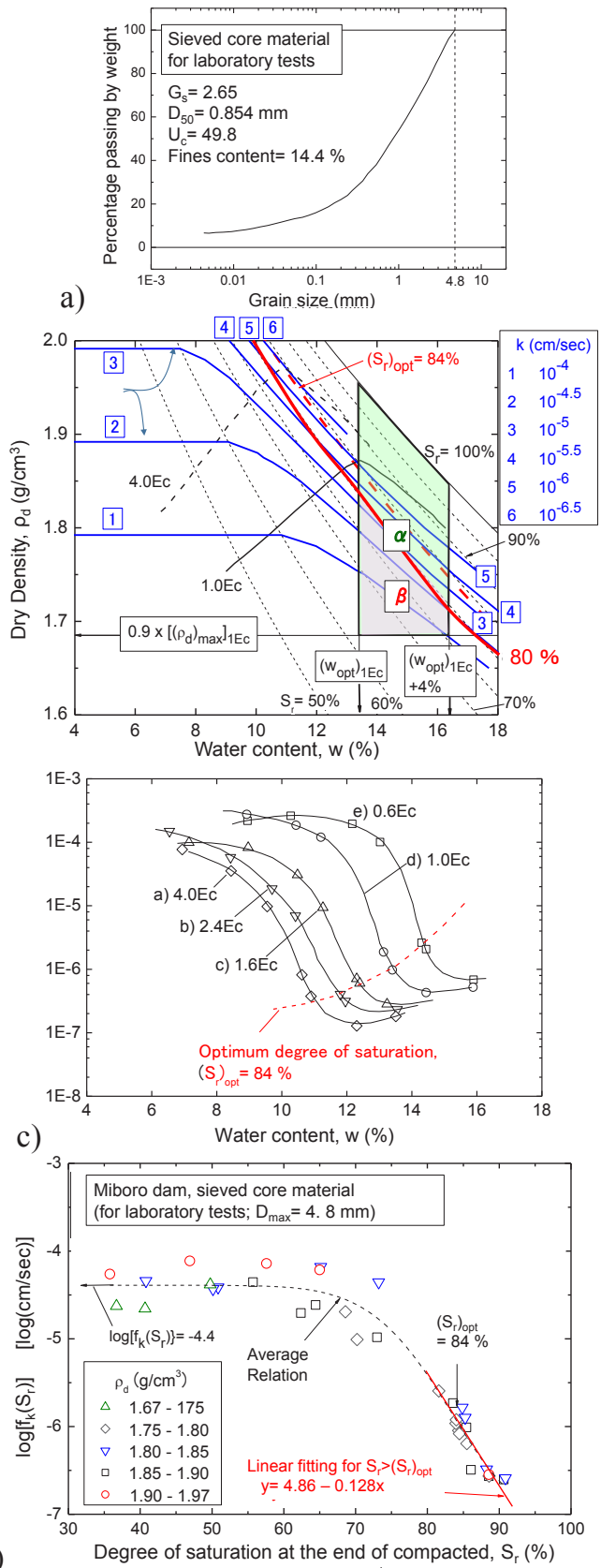

Fig. 4. a) Sieved core material for Miboro dam; b) compaction curves $(1 \mathrm{Ec} \& 4 \mathrm{Ec}), k$-contours by Eq. 3 and conventional acceptable zone $\alpha ; c) \log k-w$ relations for five different CELs (a), b) \& c) from [6]); and d) $f_{\mathrm{k}}-S_{\mathrm{r}}$ relation (analyzed in [1]).
Usually, as the field CEL is variable and unknown, it is difficult to predict the value of $k$ for a given $w$ by referring to such curves for different CELs as shown in Fig. $4 c$. On the other hand, $\left(S_{\mathrm{r}}\right)_{\text {EOC }}$, controlling pore size distribution, and $\rho_{\mathrm{d}}$, representing the total pore volume, are the two major factors for $k[1,9]$. Tatsuoka [1] fitted the data of $k(\mathrm{~cm} / \mathrm{sec})$ presented in Fig. $4 \mathrm{c}$ by Eq. 3:

$$
\log k=\log f_{k}\left(S_{r}\right)+5.02\left(1.872-\rho_{d} / \rho_{w}\right)
$$

where $f_{\mathrm{k}}$ is "the $k$ value when $\rho_{\mathrm{d}}=\left[\left(\rho_{\mathrm{d}}\right)_{\max }\right]_{1 \mathrm{Ec}}=1.872$ $\mathrm{g} / \mathrm{cm}^{3}$ ". Fig. $4 \mathrm{~d}$ shows the values of $f_{\mathrm{k}}$ obtained by substituting the values of $k$ and $\rho_{\mathrm{d}}$ of the data shown in Fig. $4 \mathrm{c}$ into Eq. 3 plotted against $\left(S_{\mathrm{r}}\right)_{\text {EOC. }}$ As the $f_{\mathrm{k}}-S_{\mathrm{r}}$ relation is rather unique for the different CELs, without referring to CEL, the $k$ value for given values of $\rho_{\mathrm{d}}$ and $S_{\mathrm{r}}$ can be obtained by Eq. $3 . f_{\mathrm{k}}$ is nearly constant when $S_{\mathrm{r}}<60 \%$ and decreases fast with $S_{\mathrm{r}}$ when $S_{\mathrm{r}}>$ about 70 $\%$. This is due likely to that the micro-structure becomes more dispersed with smaller pores as $S_{\mathrm{r}}$ exceeds a certain limit. In Fig. 4b, several contours of $k$ by Eq. 3 are depicted. Tatsuoka [1] modified Eq. 3 to take into account particle size effects on the $k$ value.

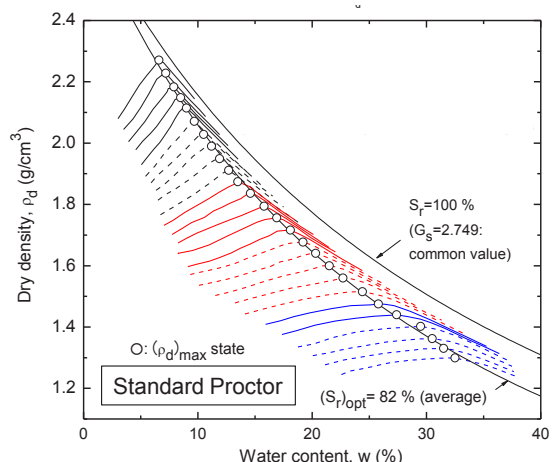

a)

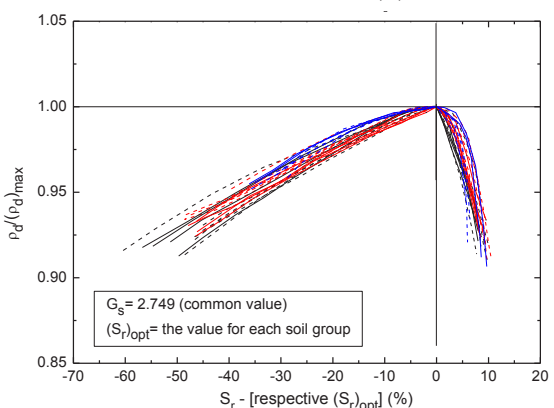

Fig. 5. a) 26 average $\rho_{\mathrm{d}}-w$ relations from 1,000 laboratory compaction tests $(1.0 \mathrm{Ec})$ by Ohio State, USA, reported in [11]; and b) $\rho_{\mathrm{d}} /\left(\rho_{\mathrm{d}}\right)_{\max }$ vs. $S_{\mathrm{r}}-\left(S_{\mathrm{r}}\right)_{\mathrm{opt}}$ relations, analyzed in $[1,2]$.

\section{Compaction characteristics}

Fig. 5a shows 26 average curves obtained from 10,000 laboratory compaction tests $(1 \mathrm{Ec})$ of a wide variety of soil types [11]. Despite a very large range of $\left(\rho_{\mathrm{d}}\right)_{\max }$, $\left(S_{\mathrm{r}}\right)_{\text {opt }}$ does not exhibit a specific trend of variation. Fig. $5 \mathrm{~b}$ shows their normalized relations; i.e., the true degree of compaction $\left[D_{\mathrm{c}}\right]_{\mathrm{t}}=\rho_{\mathrm{d}} /\left(\rho_{\mathrm{d}}\right)_{\max }$ vs. $S_{\mathrm{r}}-\left(S_{\mathrm{r}}\right)_{\text {opt }}[1]$. They are essentially unique unlike the original $\rho_{\mathrm{d}}-w$ plots. The same trend was observed with many other data sets $[1,2]$. By assuming unique $\left(S_{\mathrm{r}}\right)_{\mathrm{opt}}$ and normalized compaction curve, the value of $\left[D_{\mathrm{c}}\right]_{\mathrm{t}}$ becomes a unique function of $S_{\mathrm{r}}$ irrespective of variations in soil type and 
CEL. Moreover, Fig. 6 shows the coefficient $C$ (Eq. 1) plotted against $\left[\left(\rho_{\mathrm{d}}\right)_{\max }\right]_{1 \mathrm{Ec}}$ for various soil types. The $C$ value is generally higher with clayey soils than with sandy-gravelly soils and tends to increase with a decrease in $\left[\left(\rho_{\mathrm{d}}\right)_{\max }\right]_{1 \mathrm{Ec}}$.

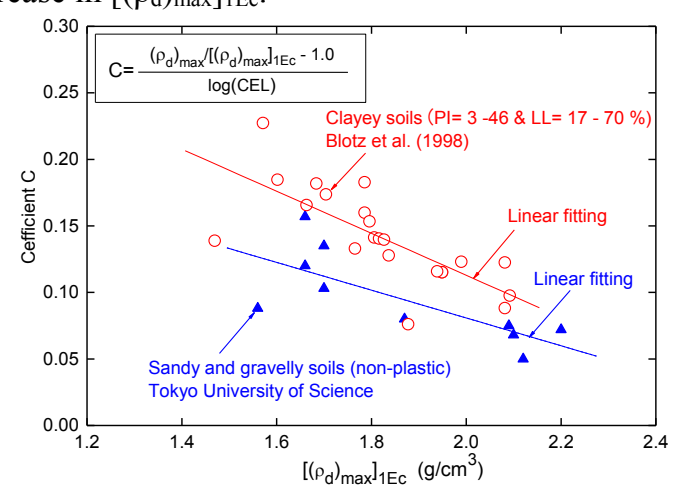

Fig. 6. Coefficient $C$ (Eq. 1) vs. $\left[\left(\rho_{\mathrm{d}}\right)_{\max }\right]_{1 \mathrm{Ec}}$ relations from laboratory compaction tests: see [1] for the references for the data presented in this figure.

The value of $\left(S_{\mathrm{r}}\right)_{\mathrm{opt}}$, the normalized compaction curve and the value of $C$ are not unique for a wide range of soil type and CEL. However, in a project where the variations of soil type and CEL are kept limited by their control, these three empirical compaction rules can be reasonably assumed to be fixed and can be determined by a limited number of laboratory compaction tests at a certain CEL using a chosen representative sample. On the other hand, the degree of compaction $\left[D_{\mathrm{c}}\right]_{1 \mathrm{Ec}}$ is defined as the ratio of field $\rho_{d},\left(\rho_{d}\right)_{f}$, to $\left[\left(\rho_{d}\right)_{\max }\right]_{1 \mathrm{Ec}}$ by laboratory compaction tests at $1 \mathrm{Ec}$, for example, using the fill material retrieved from the location where $\left(\rho_{\mathrm{d}}\right)_{\mathrm{f}}$ is measured. $\left[D_{\mathrm{c}}\right]_{1 \mathrm{Ec}}$ composes two components (Eq. 4):

$$
\begin{aligned}
{\left[D_{\mathrm{c}}\right]_{1 \mathrm{Ec}} } & =\left(\rho_{\mathrm{d}}\right)_{\mathrm{f}} /\left[\left(\rho_{\mathrm{d}}\right)_{\max }\right]_{1 \mathrm{Ec}} \\
& =\left(\rho_{\mathrm{d}}\right)_{\mathrm{f}} /\left[\left(\rho_{\mathrm{d}}\right)_{\max }\right]_{\mathrm{f}} \text { times }\left[\left(\rho_{\mathrm{d}}\right)_{\max }\right]_{\mathrm{f}} /\left[\left(\rho_{\mathrm{d}}\right)_{\max }\right]_{1 \mathrm{Ec}} \\
& =\left[D_{\mathrm{c}}\right]_{\mathrm{t}} \text { times } R
\end{aligned}
$$

where $\left[\left(\rho_{\mathrm{d}}\right)_{\max }\right]_{\mathrm{f}}$ is $\left(\rho_{\mathrm{d}}\right)_{\max }$ when compacted at CEL in the field. According to the three compaction rules, $\left[D_{\mathrm{c}}\right]_{\mathrm{t}}=$ $\left(\rho_{\mathrm{d}}\right)_{\mathrm{f}} /\left[\left(\rho_{\mathrm{d}}\right)_{\max }\right]_{\mathrm{f}}$ is a function of $S_{\mathrm{r}}-\left(S_{\mathrm{r}}\right)_{\text {opt }}$ (Fig. 5b). So, when $S_{\mathrm{r}}=\left(S_{\mathrm{r}}\right)_{\mathrm{opt}},\left[D_{\mathrm{c}}\right]_{\mathrm{t}}=1.0$ and, for a given CEL, soaked CBR becomes nearly the maximum while $k$ becomes only slightly higher than the minimum. As $R=$ $\left[\left(\rho_{\mathrm{d}}\right)_{\max }\right]_{\mathrm{f}} /\left[\left(\rho_{\mathrm{d}}\right)_{\max }\right]_{1 \mathrm{Ec}}$ is a function of field CEL (Eq. 1), when field CEL is kept sufficiently high under the control of $S_{\mathrm{r}}=\left(S_{\mathrm{r}}\right)_{\mathrm{opt}},\left[D_{\mathrm{c}}\right]_{1 \mathrm{Ec}}($ Eq. 4$)$ is kept sufficiently high to ensure the physical properties required in design.

Fig. 7 shows the framework of the soil compaction control following the concepts explained above [1, 2]. This proposal encourages compaction to $\rho_{\mathrm{d}}$ higher than the value attained in usual practice by fully taking advantage of practically achievable compaction efforts on site. Target $\mathrm{T}$ is located above the contours of soil properties (e.g., soaked CBR, Fig. 2b; and saturated $k$, Fig. 4b) required in design. It is usually relevant to specify $S_{\mathrm{r}}=\left(S_{\mathrm{r}}\right)_{\mathrm{opt}}$ at target $\mathrm{T}$. Acceptable zone A is specified to deal with inevitable variable deviations of measured compacted states from target $\mathrm{T}$, which comprises DL for $\rho_{\mathrm{d}}, \mathrm{WL}$ and WU for $w$ and SL and SU for $S_{\mathrm{r}}$. With soil structures impeding water flow, the allowable lower bound of $S_{\mathrm{r}}(\mathrm{SL})$ may be specified to be properly higher than the value at point B in Fig. 7. For example, in Fig. $4 b$, zone $\alpha$ denotes the acceptable zone often specified in usual practice. However, in zone $\beta$ (i.e., the left bottom part of zone $\alpha$ ), the $k$ value may be too high while large collapse and strength drop may take place upon wetting. In this case, zone $\beta$ can be effectively eliminated by specifying allowable lower bound SL at $S_{\mathrm{r}}=80 \%$, which is noticeably higher than the value at the left bottom corner of zone $\beta$ (i.e., point $B$ in Fig. 7). The allowable lower bound of $w(\mathrm{WL})$ is specified to avoid compaction to zone $\mathrm{E}$, which is very hard to reach while compacted soil may be too stiff. Importantly, this $w$ value at WL may be noticeably lower than the value often adopted in usual practice, typically $\left(w_{\text {opt }}\right)_{1 \mathrm{Ec}}$. The allowable upper bounds SU for $S_{\mathrm{r}}$ and WU for $w$ are to avoid too low strength/stiffness and overcompaction. As in usual practice, it is confirmed at selected locations that the apparent values of $\left[D_{\mathrm{c}}\right]_{1 \mathrm{Ec}}(\mathrm{Eq}$. $4)$, obtained from the ratio of " $\left(\rho_{\mathrm{d}}\right)_{\mathrm{f}}$ at each location" to " $\left[\left(\rho_{\mathrm{d}}\right)_{\max }\right]_{1 \mathrm{Ec}}$ of a representative sample", are higher than the allowable lower bound (typically 0.95) for DL.

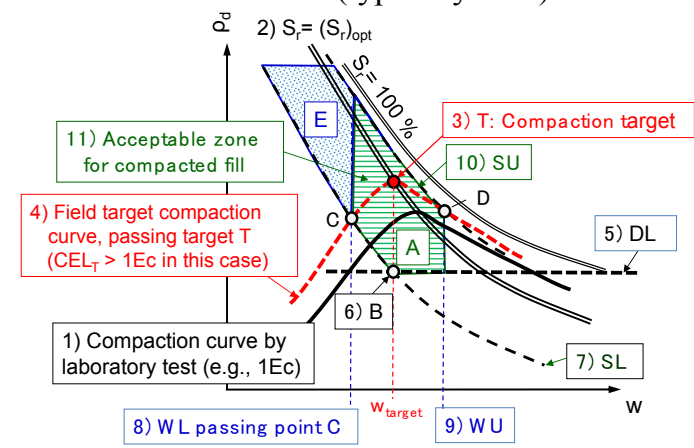

Fig. 7. Soil compaction control to ensure the soil properties required in design: the numbers denote procedure sequence [1].

\section{Earth-fill dam construction}

A case history of soil compaction following the method illustrated in Fig. 7 is herein described. The old Fujinuma main and auxilliary earth-fill dams collapsed by the 2011 Earthquake $[3-5,12]$. The dams were uniform type having no core zone. The main dam composed bottom, middle and top fills. The construction started in 1937 while the top fill was constructed immediately after World War II. The initial slide took place in the upstream slope of the top fill, followed by multiple slides in the whole top fill. The second and larger slide took place in the upstream slope of the top and middle fills. Both events triggered over-toppin flow in the highest section of the dam that resulted in breaching of the dam. Nearly the whole of the top fill, the upper half layer of the middle fill and the whole downstream slope of the middle and bottom fills were eroded. At limited places that survived this collapse, field values of $\rho_{\mathrm{d}}$ and $w$ were measured and compared with results of laboratory compaction tests performed on the materials retrievd from these places (Fig. 8). The top fill was poorly compacted sandy soil with $\left[D_{\mathrm{c}}\right]_{1 \mathrm{Ec}}=$ $87.9 \%$. With similar soil type in the old auxiliarory dam, $\left[D_{\mathrm{c}}\right]_{1 \mathrm{Ec}}$ was only $79.1 \%$. $\left[D_{\mathrm{c}}\right]_{1 \mathrm{Ec}}$ was very low also in the middle and bottom fills having larger fines contents. 
This poor compaction is due likely to very low CEL used and no modern soil compaction control. The stability analysis [3-5] indicates that this poor compaction is one of the major causes of the collapse of the old dams.

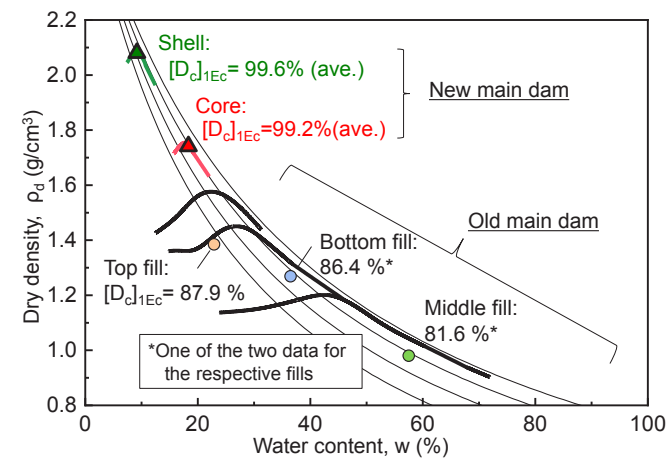

Fig. 8. Field compacted states in old and new dams (for the new main dam, the average compaction curves and the average compacted states by series $\boldsymbol{B}$ shown in Fig. 10 are presented).

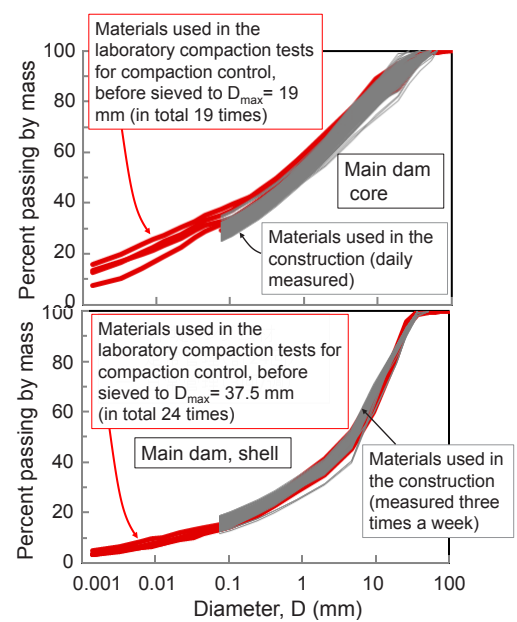

Fig. 9. Fill materials of new main dam (evaluated in series $\boldsymbol{A}$ ).

The new dams (Fig. 1) were designed based on the stability analysis [3-5] and constructed following the soil compaction control described above (Fig. 7) to be substantially more stable than the old ones. Field fullscale compaction tests were performed using a heavy vibratory tamping roller on the planned fill materials, similar to those actually used (Fig. 9). It was not feasible to perform compaction tests, stress-strain tests and permeability tests on the actual fill materials having large particles with a diameter up to $150 \mathrm{~mm}$ in the laboratory. Besides, the hydraulic conductivity $k$ of compacted core is controlled by the value of its finer particle portion. In addition, it is on the safe side to use the strength and stiffness of fine particle portion evaluated as a function of $\left[D_{\mathrm{c}}\right]_{1 \mathrm{Ec}}$ for the value of field compacted soil. Thus, these laboratory tests were performed on core and shell materials seived to $D \leq 19$ $\mathrm{mm}$ and $37.5 \mathrm{~mm}$, respectively. During the field compaction tests and the actual construction, the values of $\left[D_{\mathrm{c}}\right]_{1 \mathrm{Ec}}$ and $w$ of these fine particle portions were obtained from measured field compacted states, and these values are reported herein.

The core and shell materials for the field full-scale compaction tests were prepared at the following three $w$ values for fine particle portion: the core: $\left(w_{\mathrm{opt}}\right)_{1 \mathrm{Ec}}-1.5$ $\%,\left(w_{\mathrm{opt}}\right)_{1 \mathrm{Ec}}=18.5 \%$ and $\left(w_{\mathrm{opt}}\right)_{1 \mathrm{Ec}}+4.0 \%$; and the shell: $\left(w_{\text {opt }}\right)_{1 \mathrm{Ec}}-3.5 \%,\left(w_{\text {opt }}\right)_{1 \mathrm{Ec}}=10 \%$ and $\left(w_{\mathrm{opt}}\right)_{1 \mathrm{Ec}}+1.0 \%$. With both materials, for an initial soil layer thickness of $25 \mathrm{~cm}$, the $\rho_{\mathrm{d}}$ values after a number of pass $\mathrm{N}=8$ were slightly higher than $\left[\left(\rho_{\mathrm{d}}\right)_{\max }\right]_{1 \mathrm{Ec}}$ when $w=\left(w_{\mathrm{opt}}\right)_{1 \mathrm{Ec}}$, while compaction was poor and over-compaction took place at the highest $w$. Then, the compaction targets denoted as T in Fig. 10 were determined where $\left(S_{\mathrm{r}}\right)_{\text {target }}=\left(S_{\mathrm{r}}\right)_{\mathrm{opt}}, w_{\text {target }}=$ $\left(w_{\mathrm{opt}}\right)_{1 \mathrm{Ec}}$ and $\left(\rho_{\mathrm{d}}\right)_{\text {target }}=\left[\left(\rho_{\mathrm{d}}\right)_{\max }\right]_{1 \mathrm{Ec}}$ for both core and shell materials. To allow some scatter deviating from each target, the acceptable zones shown in Fig. 10 were speficified. With the core material, to ensure sufficiently low $k$, a relatively high average of the $w$ values at WU and WL $\left(=\left(w_{\mathrm{opt}}\right)_{1 \mathrm{Ec}}+0.5 \%\right)$ and a relatively high $S_{\mathrm{r}}$ value at $\mathrm{SL}\left(=\left(S_{\mathrm{r}}\right)_{\mathrm{opt}}-5 \%\right)$ were specified.

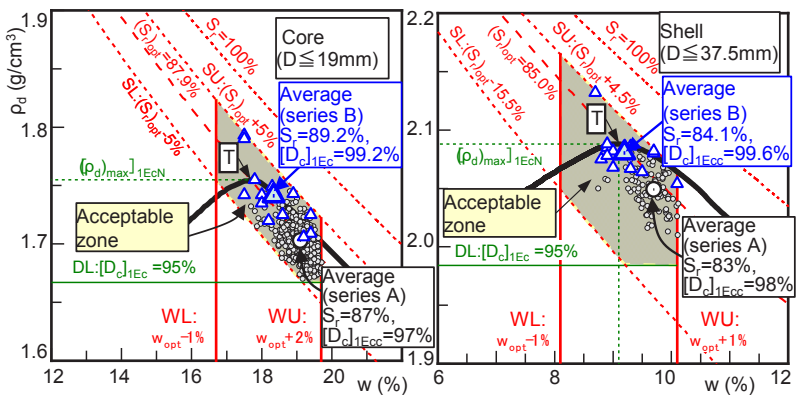

Fig. 10. Normalized compacted states, new main dam.

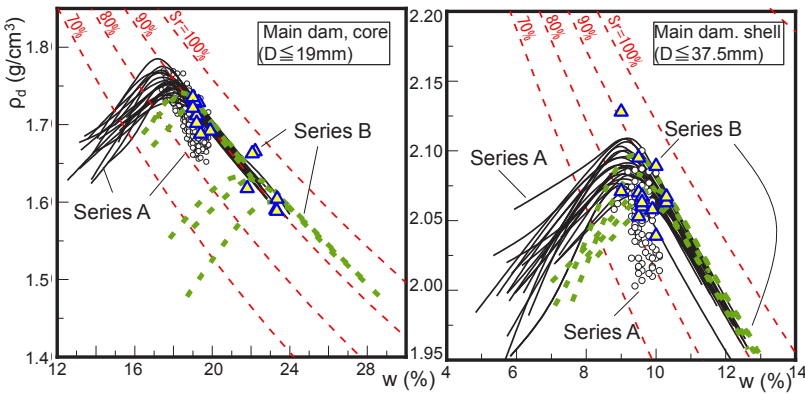

Fig. 11. Measured compacted states, new main dam.

In Fig. 11, each measured field compacted state of fine particle portion of the core or shell material is compared to the laboratory compaction curve (1Ec) obtained using either: a representative sample of each batch with a volume of about $3,000 \mathrm{~m}^{3}$ (series $\boldsymbol{A}$, performed throughout the construction); or fill material retrieved from each location where field compacted state was measured (series $\boldsymbol{B}$ ). Although series $\boldsymbol{B}$ is very timeconsuming, it was performed at limited locations to evaluate the accuracy of series $\boldsymbol{A}$. That is, a large scatter in the compacted states in series $\boldsymbol{A}$ seen in Fig. 11 is due to: (factor 1) variations in CEL and $S_{\mathrm{r}}$ in the field; (factor 2 ) a scatter of compaction curve (1Ec) due to a scatter in the soil type among different batches; and (factor 3) a scatter of soil type at different locations at which field $\rho_{\mathrm{d}}$ $\& w$ values were measured for each batch. To remove the effects of factor 2 from the plots in Fig. 11 and to compare the compacted states with the common target point and acceptable zone, these data were normalized as shown in Fig. 10. To this end, firstly it was confirmed that the $\left(S_{\mathrm{r}}\right)_{\mathrm{opt}}$ value and the normalized compaction curve are essentially unique for, respectively, the core and shell materials. Secondly, for the respective 
materials, the average of all the compaction curves by series $\boldsymbol{A}$ was obtained, as shown in Fig. 10. Thirdly, each field compacted state in series $\boldsymbol{A}$ and $\boldsymbol{B}$ shown in Fig. 11 was moved to its normalized state shown in Fig. 10 by keeping its location relative to the average compaction curve in terms of $\left[D_{\mathrm{c}}\right]_{1 \mathrm{Ec}}=\rho_{\mathrm{d}} /\left[\left(\rho_{\mathrm{d}}\right)_{\max }\right]_{1 \mathrm{Ec}}$ and $S_{\mathrm{r}}-\left(S_{\mathrm{r}}\right)_{\mathrm{opt}}$ the same as its location relative to its original compaction curve (shown in Fig. 11). In Fig. 10, all the normalized compacted states in series $\boldsymbol{A}$ are located inside the respective acceptable zones. The compaction work was approved based on this result. Yet, the average $w$ value of the normalized compacted states in series $\boldsymbol{A}$ is noticeably higher than the $\left(w_{\mathrm{opt}}\right)_{1 \mathrm{Ec}}$ value at the respective target points. It was found that this deviation tends to increase with an increase in the fines content, which is reflected in a decrease in $\left(\rho_{\mathrm{d}}\right)_{\max }$ in series $\boldsymbol{B}$ (Fig. 11). On the other hand, the results by series $\boldsymbol{B}$ presented in Fig. 10 include some effects of factor 1 but are essentially free from erroneous effects of factors 2 and 3. In Fig. 10, with both materials, the average of normalized compacted states in series $\boldsymbol{B}$ is very close to the target point $\mathrm{T}$. It seems that the representative samples used to obtain the compaction curves in series $\boldsymbol{A}$ deviated from those actually compacted in the field by missing fine particle clusters during their sampling from stock piles, resulting in $\left(w_{\mathrm{opt}}\right)_{1 \mathrm{Ec}}$ values of the representative samples lower than the actual values. In the stability analysis of the new dam [5], the average values of $\left[D_{\mathrm{c}}\right]_{1 \mathrm{Ec}}$ obtained by series $\boldsymbol{B}$ were used.

In Fig. 10 , in series $\boldsymbol{B}$, the average values of $\left[D_{\mathrm{c}}\right]_{1 \mathrm{Ec}}$ are close to the target value (i.e., $100 \%$ ) irrespective of inevitable variations of soil type in the field. As discussed related to Eq. 4, this satisfactory result can be attributed to strict control of field CEL to be high enough and constant by monitoring the movements of compaction machines by means of GPS in addition to the control of $\left(S_{\mathrm{r}}\right)_{\mathrm{EOC}}$ to be equal to $\left(S_{\mathrm{r}}\right)_{\text {opt. }}$. It was also confirmed that the design physical properties of compacted soil were controlled satisfactorily. It may be seen from Fig. 8 that both $\rho_{\mathrm{d}}$ and $\left[D_{\mathrm{c}}\right]_{1 \mathrm{Ec}}$ of the new main dam are substantially higher than those of the old main dam. Duttine et al. [5] showed significant effects of compaction on the seismic stability of earth-fill dam by performing seisimic stability analyses of the old and new main dams having largely different soil shear strengths.

\section{Concluding remarks}

Compacted $\rho_{\mathrm{d}}$ and $w$ states and design-related physical properties of compacted soil are controlled by the degree of saturation at the end of compaction $\left(S_{\mathrm{r}}\right)_{\mathrm{EOC}}$ and compaction energy level CEL, among others. So, by properly controlling $\left(S_{\mathrm{r}}\right)_{\mathrm{EOC}}$ and CEL, irrespective inevitable scatter in the soil type in the field, the compaction becomes much more efficient and objective than when not explicitly controlling $\left(S_{\mathrm{r}}\right)_{\text {EOC }}$ and CEL. This method was successfully used recently in the construction of earth-fill dams in Japan.

The authors like to express their sincere gratitude to Dr Tanaka, T., Prof Mohri, Y. (Ibaraki Univ.), Dr Duttine A. (IGI), Dr
Sandanbata, I. (Ando-Hazama) and Fukushima Prefecture for their help in performing this study.

\section{References}

1. F. Tatsuoka, Compaction characteristics and physical properties of compacted soil controlled by the degree of saturation, Keynote Lecture, Deformation characteristics of geomaterials, Proc. of $6^{\text {th }}$ Int. Conf. on Deformation Characteristics of Geomaterials, Buenos Aires, 40-78 (2015)

2. F. Tatsuoka \& A. Gomes Correia, Importance of Controlling the Degree of Saturation in Soil Compaction linked to Soil Structure Design, Transportation Geotechnics 17, 3-27 (2018)

3. F. Tatsuoka, T. Tanaka, K. Ueno, A. Duttine, \&Y. Mohri, Soil properties and seismic stability of old and new Fujinuma dams, Proc. Int. Symp. on Qualification of dynamic analyses of dams and their equipment. Saint-Malo, France (.eds. Fry, J.-J. \& Matsumoto, N.), 119-170 (2018)

4. A. Duttine, F. Tatsuoka, T. Shinbo \& Y. Mohri, A new simplified seismic stability analysis taking into account degradation of soil undrained stress - strain properties and effects of compaction, Proc. Int. Sym. on Qualification of dynamic analyses of dams and their equipment, Saint-Malo, France (eds. Fry, J.-J. \& Matsumoto, N.), 215-234 (2018)

5. A. Duttine, F. Tatsuoka \& K. Ueno, Effects of compaction on soil undrained shear strength deteriorating during undrained cyclic loading and controlling seismic stability of embankment, Proc. $7^{\text {th }}$ Int. Sym. on Deformation Characteristics of Geomaterials, IS-Glasgow (2019)

6. T. Nemoto, \& T. Sasaki, Soil compaction characteristics, Celebrating $30^{\text {th }}$ Anniversary Volume, Construction Method and Machinery Research Institute, 45-58 (in Japanese) (1994)

7. E. Mikuni, Study on the properties of fill dam core material and its compaction (No. 1), Monthly J. of JGS, Tsuchi-to-Kiso, 10(1), 4-12 (in Japanese) (1962)

8. J. Mitchell, G. Hooper \& R. Campanella, Permeability of compacted clay, $J$. of Soil Mechanics and Foundation Div., ASCE 91, 41-65 (1965)

9. D.E. Daniel \& C.H. Benson, Water content-density criteria for compacted soil liners, J. of Geotechnical Engineering 116-12, 1811-1830 (1990)

10. C.H. Benson \& J.M. Trast, Hydraulic conductivity of thirteen compacted clays, Clays and Clay Minerals, 43-6, 669-681 (1995)

11. J.G. Joslin, Ohio's typical moisture-density curves, ASTM STP239, Proc. of Symposium on Application of Soil Testing in Highway Design and Construction, 111-118 (1959)

12. T. Tanaka, F. Tatsuoka \& Y. Mohri, Earthquakeinduced failure of Fujinuma Dam, Proc. Int. Sym. on Dams for a Changing World, 24th Congress ICOLD, Kyoto, 6.47-6.52 (2012) 